\title{
The Introduction of Laparoscopic Appendectomy in a Teaching Hospital
}

\author{
M. Khoursheed ${ }^{a} \quad$ W. Sobhi ${ }^{b} \quad$ K. Al-Sharaf ${ }^{b}$ S. Aman ${ }^{b}$ \\ A. Behbehanib H. Dashtia \\ Departments of Surgery, a Faculty of Medicine, Kuwait University, and \\ bMubarak Al-Kabeer Hospital, Kuwait
}

\section{Key Words}

Appendicitis · Appendectomy · Laparoscopy

\begin{abstract}
Objectives: A retrospective study of laparoscopic appendectomy (LA) versus open appendectomy (OA) was performed on patients with suspected acute appendicitis. Patients were selected for OA or LA according to the clinical evaluation, and preference of the surgeon. Methods: Over a 2-year period 180 patients were included, of whom 94 patients underwent OA, and 86 patients underwent LA. Results: LA was successfully completed in 76 patients (88.3\%). The mean hospital stay in OA was 3.2 days versus 2.7 days in $\mathrm{LA}$. The mean operative time was shorter in OA than in LA (51.6 versus $59.8 \mathrm{~min}$ ). There was no significant difference in convalescence between both the groups, however, there was a tendency towards less narcotic requirement among the LA group. Postoperative complications in patients who underwent OA included: chest infection (3 pa-
\end{abstract}

\begin{tabular}{ll}
\hline KARGER & (1) 1999 S. Karger AG, Basel \\
Fax +41 61 306 1234 34 & \\
$\begin{array}{l}\text { E-Mail karger@karger.ch } \\
\text { www.karger.com }\end{array}$ & $\begin{array}{l}\text { Accessible online at: } \\
\text { http://BioMedNet.com/karger }\end{array}$
\end{tabular}

tients), wound infection (4 patients), thrombophlebitis (1 patient). Complications after LA included: pelvic collection (1 patient), chest infection (1 patient), ileus (1 patient). There was no wound infection in the LA group. There was no death in either groups. Conclusion: LA is a safe procedure comparable to OA, however, it requires skills in laparoscopy and prospective randomized trials are needed to confirm its advantages over conventional appendectomy.

\section{Introduction}

Open appendectomy (OA) has remained a safe and efficient procedure with low morbidity and mortality rates [1-3], until the late 1980s when laparoscopic appendectomy (LA) became widely accepted since its introduction by Semm [4] in 1983. It is clear that laparoscopy has greater diagnostic accuracy particularly in young women [5-10], and therefore avoids the removal of a normal appendix that 
may reach $40 \%$ in some reported series [3, 11-14]. The potential advantages of shorter hospital stay, less postoperative pain, decreased wound infection rate, and faster recovery after LA remained controversial for many surgeons because of conflicting data and lack of prospective randomized studies [15-21]. A few prospective randomized studies have been suggestive, but not conclusive, of the advantages of the laparoscopic approach $[16,17]$. Twelve original articles involving a randomized controlled trial on LA in adults were reviewed with regard to the methodology used, operating time, intraoperative and postoperative complications, time until resumption of diet, postoperative pain, hospital stay, cost, and quality of life analyses. This study showed that there were six positive (a procedure is superior to the other) and six negative (no difference) trials. Wound infection was more frequent after $\mathrm{OA}$, and intraabdominal abscess was more frequent after LA. This review failed to show the superiority of laparoscopy for the outcomes, particularly postoperative pain. Thus, nothing was clearly established [22]. The present study is aimed at comparing the outcome of OA and LA in patients with suspected acute appendicitis.

\section{Patients and Methods}

From January 1995 to January 1997, 180 patients with suspected appendicitis underwent laparotomy or laparoscopy. All procedures were performed in the Mubarak Al-Kabeer Teaching Hospital, and all the procedures if done laparoscopically were performed by surgeons trained in laparoscopy. The selection of patients for laparoscopic or conventional appendectomy was determined according to the clinical evaluation and the preference of the surgeon on call. Appendectomy was performed even when the appendix was judged to be normal by laparoscopy in 18 patients $(23.7 \%)$ to assess the diagnostic accuracy of laparoscopy. Prophylactic broad spectrum antibiotics were given intravenously for all cases. Operative time was defined as the time from the start of induction to extubation.
Postoperative analgesics were given intramuscularly (pethidine $1 \mathrm{mg} / \mathrm{kg}$ ) or orally as needed, and antibiotics were continued postoperatively in gangrenous and perforated appendicitis. Patients resumed oral intake if bowel function was adequate, and were discharged from the hospital when there was no evidence of sepsis. Return to normal daily activity was assessed by telephone interview.

OA was performed through transverse muscle splitting incision in the right iliac fossa. The mesentery and the base of the appendix were ligated without burying the stump.

LA was performed with the patient in a supine position via three cannulas. A pneumoperitoneum is first created by inserting a Verres needle and insufflation below the umbilicus. A 10-mm trocar is inserted below the umbilicus and the laparoscope is introduced. Under direct vision another 5-mm and 10-mm trocars are introduced in the suprapubic region and left iliac fossa consecutively. The dissection of the mesentery is performed by electrocautery and by the application of hemoclips. The base of the appendix is ligated by two endoloops before the appendix is divided in between. The specimen is retrieved from the $10-\mathrm{mm}$ port, and occasionally an endobag is used to extract the bulky specimen to decrease contamination.

Statistical Methods. Data were processed on the SPSS [23] Windows version 7. Statistical significance was set at the $5 \%$ level. The chi-square test was used to assess the association between the two categorical variables, and the Student's t test was used to assess the significance between the means of two continuous variables.

\section{Results}

Over a period of 2 years, 180 patients underwent appendectomy for suspected appendicitis. OA was performed primarily in 94 patients, and after diagnostic laparoscopy and conversion to open procedure in 10 patients. LA was attempted in 86 patients. However, it was successfully completed in 76 patients (fig. 1). The main reason for conversion in $11.7 \%$ of patients was unsuccessful dissection due to the presence of an inflammatory mass, or retrocecal appendicitis. The clinical features of patients with suspected acute appendicitis are shown in table 1.

Med Principles Pract 1999;8:138-144 139 
Fig. 1. Selection of patients for $\mathrm{OA}$

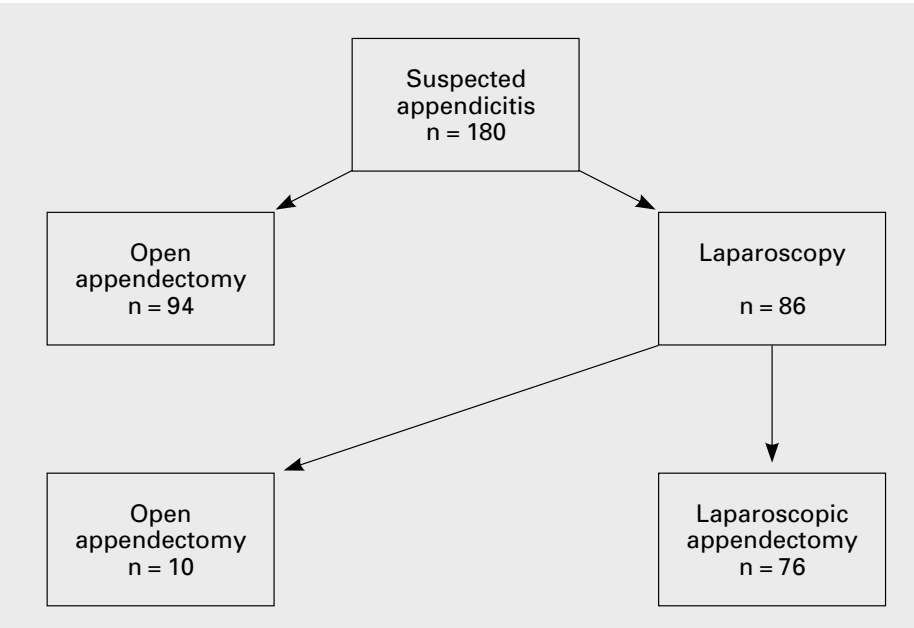
and LA.

Table 1. Frequency of symptoms and physical findings

\begin{tabular}{lrr}
\hline & \multicolumn{2}{l}{ Patients } \\
\cline { 2 - 3 } & $\mathrm{n}$ & $\%$ \\
\hline Symptoms & & \\
Right iliac fossa pain & 134 & 74.4 \\
Nausea/vomit & 113 & 62.8 \\
Anorexia & 122 & 67.8 \\
Fever & 32 & 17.8 \\
Diarrhea & 12 & 6.7 \\
Diffuse pain & 56 & 31.1 \\
\hline Signs & & \\
Localized tender & 177 & 98.3 \\
Fever $>38^{\circ} \mathrm{C}$ & 31 & 17.2 \\
Right iliac fossa mass & 3 & 1.7 \\
Diffuse peritonitis & 1 & 0.6 \\
\hline
\end{tabular}

The majority of patients who underwent OA were males ( 75 males and 19 females), and females accounted for the majority of patients in the LA group (16 males and 60 females), while in the conversion group there were 4 males and 6 female patients. These results are explained by the bias of performing more laparoscopies in women. The mean age in the OA group was 23.4 years, 28 years in the LA group, and 36.8 years in the conversion group.

Acute appendicitis was confirmed by histopathology in $88.3 \%$ of the patients, and the rest of the patients had normal appendix. However, there were more normal appendices in the LA group than in the OA group (21.1 versus $5.3 \%$ ) as confirmed by histopathology (table 2). None of the patients from the conversion group had normal appendix.

The mean operative time was $51.6 \mathrm{~min}$ (range 25-130) for the OA group compared to a mean time of 59.8 min (range 20-140) for the LA group, and 61.5 min (range 30-105) for the conversion group $(\mathrm{p}<0.05)$. The mean hospital stay in the OA group was 3.1 days (range 2-9) compared to 2.7 days (range 1-8) in the LA group $(\mathrm{p}<0.05)$. The mean hospital stay in the conversion group was 3.7 days (range 2-9, table 3). There was a reduction in the postoperative analgesia requirement among the LA group in comparison to the $\mathrm{OA}$ group (table 4). The overall morbidity in the 
Table 2. Histopathology and operative findings

Table 3. Patient details, operative time, and duration of hospital stay

Table 4. Intravenous narcotic requirement (pethidine)

\begin{tabular}{|c|c|c|c|c|c|c|}
\hline & \multicolumn{2}{|c|}{$\begin{array}{l}\mathrm{OA} \\
(\mathrm{n}=94)\end{array}$} & \multicolumn{2}{|c|}{$\begin{array}{l}\text { LA } \\
(n=76)\end{array}$} & \multicolumn{2}{|c|}{$\begin{array}{l}\text { Converted to } \\
\text { open }(n=10)\end{array}$} \\
\hline & $\mathrm{n}$ & $\%$ & $\mathrm{n}$ & $\%$ & $\mathrm{n}$ & $\%$ \\
\hline \multicolumn{7}{|c|}{ Histopathology findings* } \\
\hline Normal & 5 & 5.3 & 16 & 21.1 & 0 & 0 \\
\hline Inflamed & 89 & 94.7 & 60 & 78.9 & 10 & 100 \\
\hline \multicolumn{7}{|c|}{ Operative findings } \\
\hline Normal & 6 & 6.4 & 18 & 23.7 & 0 & 0 \\
\hline Inflamed & 77 & 81.9 & 57 & 75.0 & 6 & 60 \\
\hline Perforated & 8 & 8.5 & 0 & & 3 & 30 \\
\hline Gangrenous & 3 & 3.2 & 1 & 1.3 & 1 & 10 \\
\hline
\end{tabular}

* Significant difference $(\mathrm{p}<0.05)$ between OA and LA.

\begin{tabular}{lcll}
\hline & $\begin{array}{l}\text { OA } \\
(\mathrm{n}=94)\end{array}$ & $\begin{array}{l}\text { LA } \\
(\mathrm{n}=76)\end{array}$ & $\begin{array}{l}\text { Converted to } \\
\text { open }(\mathrm{n}=10)\end{array}$ \\
\hline Mean age, years* & $23.4 \pm 10.5$ & $28.0 \pm 10.2$ & $36.8 \pm 16.5$ \\
Sex ratio (M:F) & $75: 19$ & $16: 60$ & $4: 6$ \\
Mean operative time*, min & $51.6 \pm 18.5$ & $59.8 \pm 26.9$ & $61.5 \pm 21.7$ \\
Mean hospital stay*, days & $3.1 \pm 1.1$ & $2.7 \pm 1.17$ & $3.7 \pm 2.1$ \\
\hline
\end{tabular}

* Significant difference $(\mathrm{p}<0.05)$ between OA and LA.

\begin{tabular}{|c|c|c|c|c|c|c|}
\hline \multirow[t]{2}{*}{$\begin{array}{l}\text { Pethidine } \\
\mathrm{mg} / \mathrm{kg}\end{array}$} & \multicolumn{2}{|c|}{$\begin{array}{l}\text { OA } \\
(n=94)\end{array}$} & \multicolumn{2}{|c|}{$\begin{array}{l}\text { LA } \\
(n=76)\end{array}$} & \multicolumn{2}{|c|}{$\begin{array}{l}\text { Converted to } \\
\text { open }(n=10)\end{array}$} \\
\hline & $\mathrm{n}$ & $\%$ & $\mathrm{n}$ & $\%$ & $\mathrm{n}$ & $\%$ \\
\hline 0 & 26 & 27.7 & 38 & 50.0 & 6 & 60 \\
\hline 1 & 21 & 22.3 & 30 & 39.5 & 2 & 20 \\
\hline 2 & 25 & 26.6 & 6 & 7.9 & 0 & \\
\hline 3 & 12 & 12.8 & 1 & 1.3 & 0 & \\
\hline$>3$ & 10 & 10.6 & 1 & 1.3 & 2 & 20 \\
\hline
\end{tabular}


Table 5. Complications after appendectomy

Table 6. Return to normal activity

LA group was also lower than in the OA group (3.9 versus $8.6 \%$ ). Postoperative complications in patients who underwent OA included: chest infection (3 patients), wound infection (4 patients), and thrombophlebitis (1 patient). Complications after LA included: pelvic collection (1 patient) that resolved with antibiotics, chest infection (1 patient), ileus (1 patient: resolved with medical treatment). Only 1 patient in the conversion group developed chest infection. There was no wound infection in the LA group. There were no deaths in either of the groups (table 5).

The assessment of convalescence and return to normal activity of the patients by telephone interview was possible in $64.4 \%$ of the patients and it was hard to reach the rest of the patients at work. There was no significant difference between the groups (table 6). Al- though none of the patients from the conversion group returned to normal activity after 1 week, it was difficult to assess the significance because of the small number.

\section{Discussion}

Following the introduction of video-laparoscopy, and the improvement in instrumentation technology, LA became widely accepted, and a number of reports have looked at the feasibility and the benefits of this procedure [15-18]. Although OA is considered as a safe procedure, a larger incision is occasionally required in obese patients and complicated appendicitis, which might be cosmetically unacceptable and associated with prolonged recovery $[1,24]$. LA was successfully completed 
effectively in our study in $88.3 \%$ without any major operative complication similar to previous reports [16-18, 25-28]. Most of the conversions were during the first stages of the study, and as experience developed, the conversion rate has reduced.

Due to the bias in selecting patients for laparoscopy, $23.7 \%$ of our patients did not have acute appendicitis on laparoscopy, and this was proven in $21.1 \%$ of patients by histopathological examination. On the other hand only $5.3 \%$ of patients who had OA had histologically proven normal appendix. This emphasizes the significance of laparoscopy in the evaluation of patients with equivocal symptoms, and when the diagnosis is in doubt. As an initial procedure, laparoscopy is associated with low morbidity, and it can be converted to open procedure if needed.

Appendectomy eliminates the possibility of appendicitis if pain recurs in the future, particularly in patients without alternative diagnosis. In a prospective study [29], 19\% of appendices thought to be normal by the operating surgeon were found to have acute inflammation on subsequent histological examination. Moreover, in $77 \%$ of the appendices with carcinoid and carcinomas, the diagnosis was missed macroscopically. Our results suggest that the macroscopically normal appendix should not be removed as suggested by others [29].

The mean operative time was significantly longer for patients after LA $(p<0.05)$, but the mean hospital stay was significantly shorter $(\mathrm{p}<0.05)$, which is comparable to previous reports [16, 17, 19, 27, 30-32]. Furthermore, the operative time as well as the hospital stay were longer in the conversion group.

We have been able to show a tendency towards less postoperative narcotic requirement after LA, although there was no significant difference in convalescence and return to normal activity as reported by others [33].

Laparoscopic Appendectomy in a Teaching Hospital
Our morbidity rate in the LA group was less than in conventional surgery (3.9 versus $8.6 \%$ ), and although none of the patients in the LA group had wound infection, as against $4.3 \%$ wound infection in the OA group, these results should be interpreted with caution since $11.7 \%$ of the patients who had OA were found to have gangrenous or perforated appendicitis compared to 1 patient who had gangrenous appendicitis removed by laparoscopy. This again reflects the bias in selecting patients for each procedure. In the laparoscopy group, 1 patient developed postoperative pelvic collection that was resolved with antibiotic therapy.

In conclusion, LA is a safe procedure, however, it requires laparoscopic skills. Although our results have shown a shorter hospital stay and less narcotic requirements after LA, the convalescence of patients was similar in both groups. A randomized controlled study is required, and the issue of cost/benefit ratio remains to be addressed. 


\section{References}

1 Jess P, Bjerregaard B, Brynitz S: Acute appendicitis: Prospective trial concerning diagnostic accuracy and complications. Am J Surg 1981;141: 232-234

2 Seal A: Appendicitis: A historical review. Can J Surg 1981;24:427-433.

3 Lewis FR, Holcroft JW: Appendicitis: A critical review and treatment of 1000 cases. Arch Surg 1975;110: 677-684.

4 Semm K: Endoscopic appendectomy. Endoscopy 1983;15:59-64.

5 Paterson-Brown S: Emergency laparoscopic surgery. Br J Surg 1993;80: 279-283.

6 Spirtos NM, Eisenkop SM, Spirtos TW, Poliakin RI, Hibbard LT: Laparoscopy - a diagnostic aid in cases of suspected appendicitis: Its use in women of reproductive age. Am J Obstet Gynecol 1987;156:90-94.

7 Clarke PJ, Hands LJ, Gough MH, Kettlewell MGW: The use of laparoscopy in the management of right iliac fossa pain. Ann R Coll Engl 1986;68:68-69.

8 Anderson JL, Bridgewater FHG: Laparoscopy in the diagnosis of acute lower abdominal pain. Aust N Z J Surg 1981;51:462-464.

9 Deutch AA, Zelikovsky A, Reiss R: Laparoscopy in the prevention of unnecessary appendectomies: A prospective study. Br J Surg 1982; 69:336-337.

10 Lujan Mompean JA, Robles Campos R, Parrilla Paricio P, Soria Aledo V, Garcia Ayllon J: Laparoscopic versus open appendectomy: A prospective assessment. Br J Surg 1994; 81:133-135.

11 Izbiki JR, Koefel WT, Wilker DK: Accurate diagnosis of acute appendicitis: A retrospective and prospective analysis of 686 patients. Eur J Surg 1992;158:227-231.
12 Pieper R, Kager L, Nasman P: Acute appendicitis: A critical study of 1018 cases of emergency appendectomy. Acta Chir Scand 1982;148: 51-62.

13 Silberman VA: Appendectomy in a large metropolitan hospital: Retrospective analysis of 1013 cases. Am J Surg 1981;142:615-618.

14 Blair NB, Bugis SP, Turner LJ, McLeod MM: Review of the pathologic specimens. Am J Surg 1993; 165:618-620.

15 Soper NJ, Brunt LM, Kerbl K: Laparoscopic general surgery. N Engl J Med 1994;330:409-419.

16 Attwood SE, Hill AD, Murphy PG, Thorntn J, Stephens RB: A prospective randomized trial of laparoscopic versus open appendectomy. Surgery 1992;112:497-501.

17 McAnena OJ, Austin O, O'Connell PR, Hederman WP, Gorey TF, Fitzpatrick J: Laparoscopic versus open appendectomy: A prospective evaluation. Br J Surg 1992;79:818-820.

18 Richards W, Watson D, Lynch G: A review of the results of laparoscopic versus open appendectomy. Surg Gynecol Obstet 1993;177:473-480.

19 Pier A, Gotz F, Bacher C: Laparoscopic appendectomy in 625 cases: From innovation to routine. Surg Laparosc 1991;1:8-13.

20 Nowzaradan Y, Westmoreland J, McCarver CT, Harris RJ: Laparoscopic appendectomy for acute appendicitis: Indications and current use. J Laparoendoscopic Surg 1991; 1:247-257.

21 Levard H: Appendectomy by laparoscopy. Br J Surg 1992;79(suppl): S6.

22 Slim K, Pezet D, Chipponi J: Laparoscopic or open appendectomy? Critical review of randomized, controlled trials. Dis Colon Rectum 1998;41:398-403.
23 SPSS for Windows: User Manual, release 7.01. SPSS, Chicago, 1995.

24 Copperman M: Complications of appendectomy. Surg Clin North Am 1983;63:1233-1240

25 Pier A, Gotz F, Bacher C, Ibald R: Laparoscopic appendectomy. World J Surg 1993;17:29-33.

26 Schirmer BD, Schmieg RE Jr, Dix J: Laparoscopic versus traditional appendectomy for suspected appendicitis. Am J Surg 1993;165:670-675.

27 Tate JJ, Chung SC, Dawson J: Conventional versus laparoscopic surgery for acute appendicitis. Br J Surg 1993;80:761-764.

28 Ludwig KA, Cattey RP, Henry LG: Initial experience with laparoscopic appendectomy. Dis Colon Rectum 1993;36:463-467.

29 Lau WY, Fan ST, Yiu TF: The clinical significance of routine histopathologic study of the resected appendix and safety of appendiceal inversion. Surg Gynecol Obstet 1986; 162:256-258.

30 Cox MR, McCall JL, Padbury RT, Wilson TG, Watchow DA, Toouli J: Laparoscopic surgery in women with a clinical diagnosis of acute appendicitis. Med J Aust 1995;162: 130-132.

31 Buckley RC, Hall TJ, Muakkassa FF, Anglin B, Rhodes FS, Scott Conner CE: Laparoscopic appendectomy: Is it worth it? Am Surg 1994;60; 30-34.

32 Schorder DM, Lathrop JC, Lloyd LR: Laparoscopic appendectomy for acute appendicitis: Is there really any benefit? Am Surg 1993;59:541547.

33 Tate JJ, Dawson JW, Cung SC: Laparoscopic versus open appendectomy: Prospective randomized trial. Lancet 1993;342:633-637. 